\title{
Efficacy of Purified Glutathione-S- Transferee in Providing Protection against Haemonchus Contortus Infection in Sheep
}

\author{
Kandil $\mathrm{OM}^{1}$, Salama DB${ }^{1}$, ELmetenawy $\mathrm{TM}^{1}$, Mousa $\mathrm{WM}^{3}$ and Aboelhadid SM${ }^{*_{2}}$ \\ ${ }^{1}$ Department of Parasitology and Animal Diseases, National Research Centre (NRC), El-Behouth Street, Dokki, Giza, \\ Egypt \\ ${ }^{2}$ Parasitology Department, Faculty of Veterinary Medicine, Beni-Suef University, Beni-Suef, Egypt \\ ${ }^{3}$ Parasitology Department, Faculty of Veterinary Medicine, Cairo University, Cairo, Egypt
}

*Corresponding author: Aboelhadid SM, Department of Parasitology, Faculty of Veterinary Medicine, BeniSuef University, Egypt 62511, Tel: +201013694081, E-mail: drshawky2001@yahoo.com

Citation: Kandil OM, Salama DB, ELmetenawy TM, Mousa WM, Aboelhadid SM (2018) Efficacy of Purified Glutathione -S- Transferee in Providing Protection against Haemonchus Contortus Infection in Sheep. J Vet Sci Ani Husb 6(3): 305. doi: 10.15744/2348-9790.6.305

Received Date: May 03, 2018 Accepted Date: August 22, 2018 Published Date: August 24, 2018

\begin{abstract}
The efficacy of purified glutathione-s-transferase (GST) to protect sheep against haemonchosis was assessed. Fifteen lambs, 3.5-5monthold, were bisected into five groups $(n=3)$. Two groups were vaccinated with $250 \mu \mathrm{g}$ of each prepared antigen (crude adult antigen (CAA), purified GST) in combination with mineral oil adjuvant at zero, $14^{\text {th }}$ days of the experiment. The other three groups were kept as control groups; non-immunized infected, non-immunized non-infected and adjuvant control. One week after the last booster dose, the lambs in all groups except control negative were challenged with $400 \mathrm{~L} 3 / \mathrm{kg}$ live weight orally. Protein characterization of each antigen was done by SDS-PAGE and immunoblting. The vaccine efficacy was estimated by the fecal egg count, where the vaccinated groups showed $58.90 \%$ and $79.38 \%$ reduction in eggs in CAA and GST respectively. Moreover, $31.45 \%$ and $92.10 \%$ reduction in abomasal worm count was reported in CAA and GST vaccinated lambs, respectively. The protection was found corresponsive to the sera antibody levels in the immunized groups. It was concluded that the GST had protective efficacy against $H$. contortus infection in lambs.
\end{abstract}

Keywords: Haemonchus contortus; Sheep; GST; Fecal egg count; Worm burden; ELISA

\section{Introduction}

Haemonchus contortus ( $H$. contortus) is a bloodsucking nematode inhabits the abomasum of sheep and goats. It has been categorized as the most important parasite of small ruminant worldwide [1]. This nematode causes huge financial losses in sheep industry besides altering the well-being of their host [2]. The main way for controlling of such nematode is accomplished by the use of anthelmintic medications that provide $>99 \%$ efficacy [3]. Nevertheless, among the drawbacks of using this approach include environmental contamination and the drug residues in the marketable product $[4,5]$. In addition, anthelminthic resistance developed against new successive class of the drug [6]. Consequently, noticeable efforts have exerted towards the development of state-of-the art vaccines [7]. The accessibility of successful antiparasitic vaccine would insert a major novel protective weapon added to the other methods used for the management and control of infection in sheep [8]. Immunization with crude extract of H. contortus and proteins purified from it provides a prospective source of protective immunity [9]. The glutathione S-transferases (GSTs) are a multipurpose protein included cellular detoxification and/or by binding to a wide range of toxic molecules [10]. Reviewed parasitic GST for its role in detoxification through involved in removing of endogenous toxic compounds or reactive oxygen species of the host immune-initiated [11]. It also, has a role in transportation or metabolism of the essential materials for parasites life. It plays a critical role in detoxify cytotoxic immune-initiated products of lipid peroxidation [12]. Consequently, its protective effects against some parasites considered it a potential target for pharmaceutical and vaccine purposes [13]. The GST was predominantly abundant in $H$. contortus and has a partial protective effect against its infection [14,15]. Using of GST in different forms has variable protective efficacy against helminths; lymphatic filariasis Schistosoma japunicum and Trichenella spiralis [1619]. In addition, other studies showed that GSTs from schistosomes and cestodes are antigenic and immunogenic and provide variable degrees of protection to animals following experimental infection [20,21]. Moreover, used GST antigen for diagnosis of Haemonchosis in sheep [22]. The present study aimed to investigate the potential protective effect of purified $H$. contortus GST compared to the crude adult antigen against challenge with $H$. contortus in lambs. 


\section{Material and Methods}

\section{Ethical approval}

The procedures in all experimental native breed animals were performed in agreement with the recommendations and guidelines stated by the ethical Committee of the National Research Centre under certificate number (16050).

\section{H. contortus isolate}

Adult worms of $H$. contortus were collected from all abomasal content of infected sheep at El-monib slaughter house, Giza, Egypt according to [23]. Intact washed worms were incubated at $37^{\circ} \mathrm{C}$ for $2-3 \mathrm{hr}$ to obtain eggs. Eggs were then used in fecal culture to recover third larval stage.

\section{Crude adult and GST antigens preparation}

The crude adult antigen was prepared from the collected worm as stated by [24]. The purification of $H$. contortus adult GST was done as reported by [25]. Briefly, the sepharose 4B column (GE Healthcare., UK) was applied for GST purification. Equilibration of glutathione sepharose was conducted through $4 \mathrm{~B}$ packed column using Tris buffer (Tris- $\mathrm{Hcl} \mathrm{pH} 8$ ). The crude extract of adult worms was dispensed onto the column. Then it was washed to remove unbound fractions by equilibration buffer. The elution buffer (50 MmTris-Hcl, $10 \mathrm{mM}$ Glutathione reduced $\mathrm{pH}$ 9.6) was used on the column to elute the glutathione bound fractions in $1 \mathrm{ml}$ fractions. The latter was pooled and subjected to further dialysis concentration using polyethylene glycol (MW 8000). The specific activity of purified GST was determined according to using 1-chloro-2, 4-dinitrobenzene (CDNB) as a substrate [26]. The CDNB molar extinction is $0.0096 \mu \mathrm{M}-1 / \mathrm{cm}$. The purified GST was stored at $-20{ }^{\circ} \mathrm{C}$ until use. The protein amount in the CA and GST antigens was detected according to [27].

\section{Preparation of hyper- immune sera}

Nine healthy white New Zealand male rabbits were classified into three groups, each group contained three rabbits; first group was inoculated with CA antigen and second group was injected with GST according to and the third one used as control negative rabbit [28]. Briefly, $200 \mu \mathrm{g}$ of each prepared antigens emulsified with an equal amount of mineral oil was injected subcutaneously in each rabbit. After two weeks, two booster dosages were injected subcutaneously with a week interval. After one week from the last booster dose, sera samples were collected and stored at $-20^{\circ} \mathrm{C}$.

\section{Western blot hybridization}

The different antigens were analyzed under reducing condition on 10\% SDS-PAGE each lane was loaded with $70 \mu \mathrm{g}$ protein and subsequently stained with Coomassieblue according to the method described by [29]. The protein bands were electro-blotted on nitrocellulose paper as described by using mini trans-blot electrophoretic transfer cell (Biorad, USA) to react with the hyper immune sera against each antigen [30].

\section{Experimental immunization of lambs}

Fifteen male native lambs, 3.5-5 months of age (20-25Kg weight), kept in our amenities under strict hygienic measures, were segregated in to five groups. The first and second groups (each of $n=3$ ) were vaccinated with $250 \mu$ g of each prepared antigen emulsified in $1 \mathrm{ml}$ of mineral oil adjuvant. Booster dose was done with the same dose at 14 day first immunization. One week after the last dose, the lambs were challenged with $400 \mathrm{~L} 3 / \mathrm{kg}$ live weight (H. contortus third larvae) for each lamb orally with buccesophgeal catheter according to [15]. The third group $(n=3)$ received the mineral oil adjuvant only then subjected to the challenge infection at the main time. The fourth group $(n=3)$ received the challenge infection only as positive control. The fifth group $(n=3)$ was kept uninfected unimmunized as control negative. Sera were collected weekly from each lamb from 0 day until the end of the trial to estimate antibodies titer during the experiment.

\section{Vaccination evaluation}

The protection level was evaluated by measuring sera anti- CAA, GST antibody levels, fecal egg output reduction \%, worm burden in abomasum and the hematocrit value as described by [31].

Parasitological parameters (Fecal egg count, worm burden and establishment rate): Samples of feces were collected on the expected days for egg appearance $(16,17,18,20,21,22$ post challenge) then, weekly till the end of experiment. Egg count for each animal in the group was carried out weekly, from the onset of egg shedding until the $10^{\text {th }}$ week post challenge. The fecal samples were collected rectally and were examined by using the salt flotation technique then egg count per gram feces (epg) was done through McMaster technique according to [23]. At the end of the experiment, all animals were sacrificed at the local slaughter house. The abomasa were taken in ice tank to the laboratory to estimate the adult parasite burden. The abomasum was washed carefully with warm normal saline solution to eliminate adhering worms and the worm count was done [32]. The establishment rate was calculated by dividing the abomasal worm count upon the infective dose and multiplied by 100 . 
Immunoglobulins measurement by ELISA: ELISA was performed according to [33]. Antigen concentration and sera dilutions were determined checkerboard titration. Sera samples from immunized lambs were collected at weekly intervals from 0 to 14 weeks of the experiment. ELISA plates were coated with a $100 \mu \mathrm{l}$ of each antigen (CAA or GST), which was diluted in carbonate bicarbonate buffer ( $\mathrm{pH}$ 9.6) as $2 \mu \mathrm{g} /$ well and incubated at $4{ }^{\circ} \mathrm{C}$ overnight. Tested sera was diluted at 1:100 with dilution buffer (Phosphate buffer saline, $0.05 \%$ Tween 20), consequently incubated with a 1:1000 dilution of donkey anti-sheep peroxidase labelledIgG (whole molecule) (Sigma-Aldrich, USA) in (Phosphate buffer saline, 0.05\% Tween 20). After washing in PBS-Tween20, $50 \mu \mathrm{l}$ of O-Phenylenediamidine (OPD) (Sigma chemicals) was added and incubated in dark place till color appearance. The reaction was hindered by adding $50 \mu \mathrm{l}$ / well of $1 \mathrm{~N} \mathrm{Na} \mathrm{OH}$. The optical densities (OD) were read with a micro-ELISA reader system at 450 nm.

\section{Statistical analysis}

All the records (Worm burden, EPG and ELISA titers) were statistically analyzed by using SPSS 16.0 and were expressed as the mean \pm SEM (Standard Error of the Mean). Statistical analyses were carried out by the One Way ANOVA. Differences were considered significant at $p<0.05$.

\section{Results}

\section{Electrophoretic pattern of prepared antigens}

Gel electrophoresis of the two antigens indicated various protein bands at different molecular weight. The electrophoretic profile of CAA showed 23 protein bands (175 to $15.5 \mathrm{KDa}$ ). While GST antigen characterization gave 2 epitopes with molecular weight 23.2 and $24 \mathrm{KDa}$. Analysis of the resultant band demonstrated that there was common band between CAA and GST, 24 $\mathrm{KDa}$. The immune-blot reaction against rabbit sera showed that antigenic bands recognized positive sera using CAA contains 13 immunogenic reactive bands ( 175 to $18.6 \mathrm{KDa}$ ) while GST antigen has 2 bands $(24.6$ and $26 \mathrm{KDa})$. The common band in immunoblotting between CAA and GST was $24.6 \mathrm{KDa}$ (Figure 1).

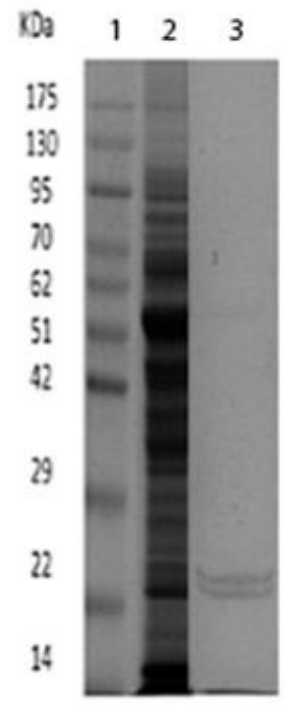

A

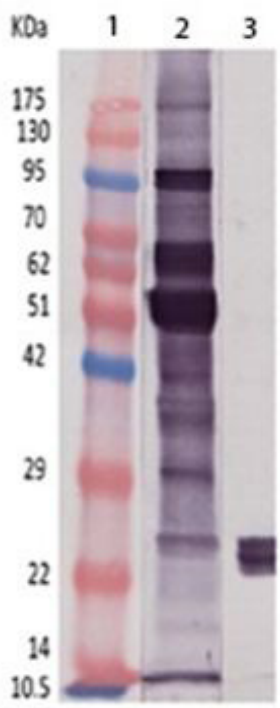

B

Figure 1: (A) The protein profile of CAA and GST antigens demonstrated by 10\% SDS-PAGE. Lane M, M.W pre-stained protein marker in KDa Lane 1, CAA antigen, lane2, GST antigen; (B) Western blot analysis of CAA and GST antigens (Lane M, M.W pre-stained protein marker in KDa,Lane1,CAA, Lane 2,GST antigen)

\section{Vaccination evaluation}

Parasitological parameters: The egg shedding in feces appeared at the $18^{\text {th }} \mathrm{dpi}$ in adjuvant and control infected unimmunized groups. While in CAA and GST immunized groups, the eggs appeared at the $28^{\text {th }}$ and $22^{\text {nd }} \mathrm{dpi}$, respectively. The mean count of eggs per gram feces (epg) in control groups reached the peak at the $6^{\text {th }}$ week post challenge. While the peak in egg count in immunized groups reached at $7^{\text {th }}$ week post infection. From the $5^{\text {th }}$ week post infection, there was a significant difference in egg count until the end of the experiment between the vaccinated groups ( $p<0.001$ ) (Figure 2 ). The reduction in epg was $59.90 \%$ and $79.38 \%$ in CAA and GST immunized groups, respectively (Table 1). Regarding, the cumulative FEC, vaccinated lambs had lower values than control groups (adjuvant and infected) lambs (Table 1). GST vaccinated animals had the lowest elimination in compared to the CAA vaccinated lambs. Furthermore, the GST immunized group showed $92.10 \%$ reduction in worm burden and it was significantly higher than CAA immunized group (31\%) (Table 2). Moreover, the establishment rate was significantly low in GST group $(2.13 \%)$ in comparison with other groups. 


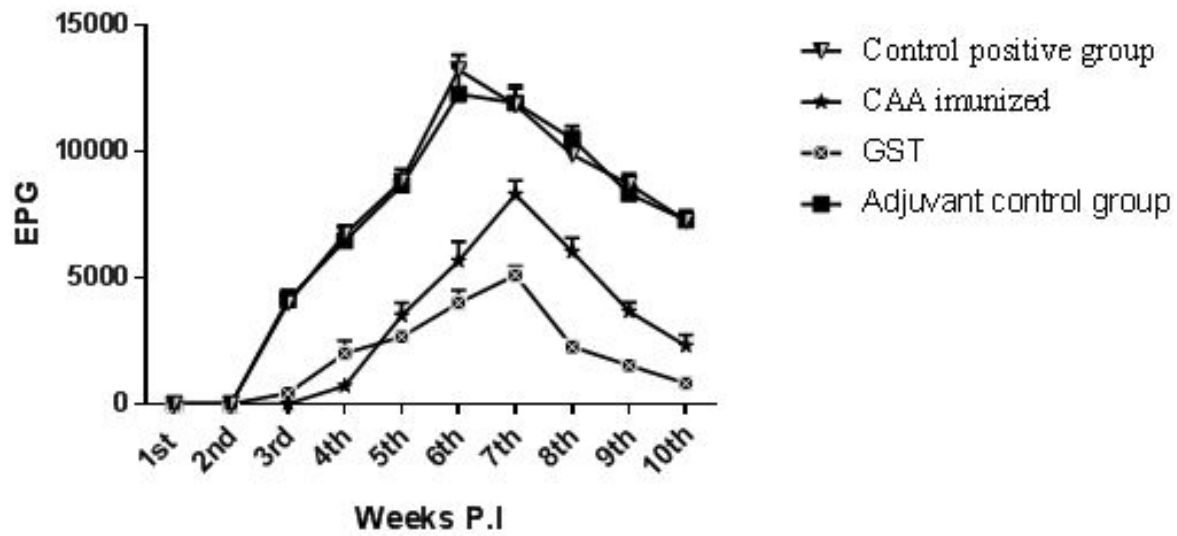

Figure 2: Egg count in all groups along the experiment, egg appeared from the $18^{\text {th }}$ day post infection in control groups (infected non-immunized and adjuvant). It appeared at the 28th day PI in the CA immunized group and at $22^{\text {nd }}$ day PI in GST immunized lambs

\begin{tabular}{|c|c|c|c|c|}
\hline Item & CAA immunized group & GST immunized group & Adjuvant control group & $\begin{array}{c}\text { Control infected } \\
\text { non-immunized group }\end{array}$ \\
\hline Cumulative egg count & $31079+3400$ & $15601+2350$ & $68632+7570$ & $75603+7860$ \\
\hline Reduction \% in egg count & 59.90 & 79.38 & 9.22 & 0.00 \\
\hline
\end{tabular}

Table 1: Cumulative fecal egg count along the experiment and reduction percentage in the egg count in different groups

\begin{tabular}{|c|c|c|c|c|c|}
\hline Group & Female worms & Male worms & Total worm burden & $\begin{array}{c}\text { Establishment rate } \\
\text { (worm burden/infective dose) \% }\end{array}$ & Worm burden reduction \% \\
\hline CAA immunized group & $1060.6 \pm 6.2^{\mathrm{a}}$ & $630.3 \pm 7.3^{\mathrm{a}}$ & $1700.0 \pm 12.5^{\mathrm{a}}$ & 21.25 & 2.13 \\
\hline GST immunized group & $110.3 \pm 3^{\mathrm{b}}$ & $60.3 \pm .3^{\mathrm{b}}$ & $170.6 \pm 0.3^{\mathrm{b}}$ & 27.40 & 31.00 \\
\hline Adjuvant control group & $1250.0 \pm 14.4^{\mathrm{c}}$ & $940.6 \pm 5.2^{\mathrm{c}}$ & $2190.6 \pm 19.2^{\mathrm{c}}$ & 11.45 \\
\hline $\begin{array}{c}\text { Control infected non- } \\
\text { immunized group }\end{array}$ & $1400.0 \pm 11.6^{\mathrm{c}}$ & $1080.0 \pm 9.9^{\mathrm{c}}$ & $2480.0 \pm 21.4^{\mathrm{c}}$ & $<0.001$ \\
\hline $\mathbf{P}$ & $<0.001$ & $<0.001$ & $<0.001$ & $<$ \\
\hline
\end{tabular}

Small letters represent differences between groups in the same column

$\mathrm{P}=$ probability value between groups

$\mathrm{CAA}=$ Crude adult antigen

GST $=$ glutathione $-\mathrm{S}$ - transferase antigen

Table 2: Mean of worm burden reduction percentage after post-mortem examination of experimentally infected sheep \pm stander error

The immunoprotective efficacy detection against used antigens by ELISA: Immunization with GST and CAA elicited a strong IgG antibody $(\mathrm{Ab})$ specific response against GST \& CAA in the vaccinated groups (Figure 3). The antibody titer increased by time

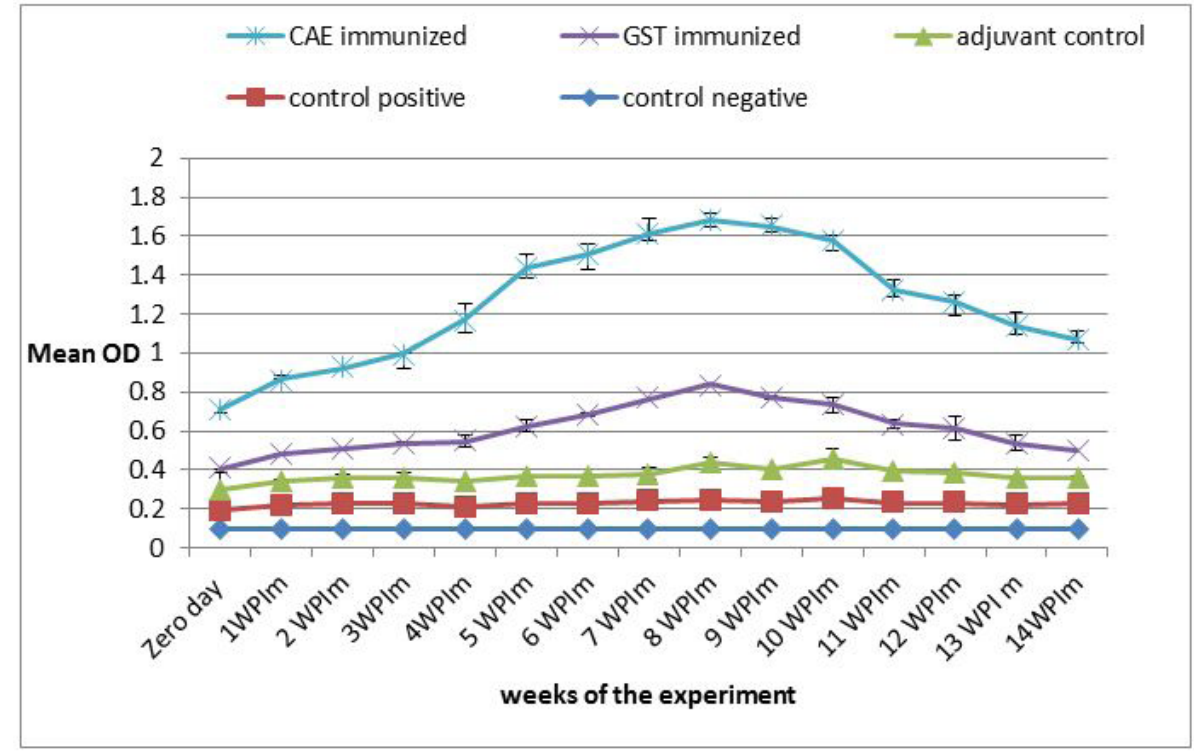

Figure 3: ELISA mean optical density of CA immunized, GST immunized, control positive group and adjuvant control groups for detection of antibody levels at zero day, after 3 week post immunization (WPIm) and a weekly intervals until the $10^{\text {th }}$ weeks post infection 
until reach the peak at the $4^{\text {th }}$ and $5^{\text {th }}$ weeks post infection in GST and CAA respectively then declined at the end of the experiment. The immunized lambs had significantly Ab levels higher than infected unimmunized one $(p<0.05)$. Moreover, CAA vaccinated lambs were significantly different to non-vaccinated group through the whole period of the experimental. While, GST immunized lambs showed a less sustained $\mathrm{Ab}$ response in compare to CAA. In addition, the infected unimmunized group did not elicit any significant $\mathrm{Ab}$ titer without any difference with uninfected control group. In addition, the OD highest average value was found in the lambs receiving CAA.

\section{Discussion}

In present study, glutathione affinity chromatography successfully isolated GST protein from $H$. contortus. In addition, the immuneblot reaction showed common band between CAA and GST (24.6 KDa). This result was similar to GST of other helminthes; it was as a single band for Ancylostoma. caninum (24KDa) and was $24 \mathrm{KDa}, 26 \mathrm{KDa}$ and $24 \mathrm{KDa}$ for Hymenolepis diminuta, Fasciola hepatica and H. contortus L3, respectively $[12,34]$. The GST antigen was used in early diagnosis of $H$. contortus infection and they added that GST has an immunogenic protein with detection of Abs as early as two weeks post-infection [22]. However, the SDSPAGE and western blot of GST showed a band around $24 \mathrm{KDa}$. This band was considered an immunogenic band as it stimulated IgG production $[22,35,36]$.

The previous studies on GSTs from helminthes were documented its induction of immune protection, Fasciola hepatica, Seteria cervi and Echinococcus granulosus [37-39]. Therefore, here in, a trial for lamb vaccination by purified GST of H. contortus was conducted. The results showed reduction of worm burden percentage and egg count for CAA immunized group (58.9\% and 79.38\% respectively). In the same time, GST immunized group caused major reduction in worm and epg ( $92.10 \%$ and $79.38 \%$ respectively). Moreover, the pre-patent period extended to 28 and 22 dpi in CAA and GST immunized groups respectively in comparison to infected unimmunized lambs and adjuvant control groups. Our results found that the immunized sheep were partially protected against haemonchosis. These results were in accordance with results of previous studies in lamb's immunization by adult somatic, larval and excretory secretory antigens $[8,22,40,41]$. The GST of other helminthes recorded remarkable results of protection; for Setaria cervi for Schistosoma, Wuchereria bancrofti, Fasciola gigantica and N. americanus [16-18,42,43]. Recently, clinical trials were conducted using the Na-GST-1 from Necator americanus in Brazilian and American volunteers [44,45]. On contrast, no protection was reported when used crude adult extract [46]. Moreover, ineffectiveness of GST was recorded in vaccination trial against $H$. contortus [47]. Additionally, H. contortus GST concerning binding and/or transporting heme-related compounds and hadn't protective effect in parasite infection [35]. They added that the lake of protection attributed to production of low titer of anti GST antibodies. We think that the latter finding of controversially may be refer to the method of GST preparation in which herein it is purified GST.

Referring to the abomasal worm burden is among the important parameters that categorized to evaluate any vaccine trial against $H$. contortus. Herein, it is high (92.10\%), this result was higher than recorded by who recorded it was $71 \%$ by using rHc23 vaccination [31]. It is constant that GST is an essential protein for parasite development and survival. Where found that H. contortus L3s resist desiccation due to Hc-gst protect it from oxidative damage via enzymatic antioxidant defense mechanism. In addition, GST is belonging to a well-known family of cytosolic enzymes involved in detoxification [48,49]. Furthermore, the reduction in adult abomasal worm count may be referring to the anti-GST antibodies could be neutralized GST enzyme activity leading to a significant disturbance in its function. The detoxyfication of hematin is corrupted. The oxidative iron in hematin damages the parasite which leads to reduction in worm burden in the immunized animals [34,50]. Moreover, the schistosome GST is accessible to host immune system due to it is an excretory secretory protein [51]. Additionally, the low epg and reduced worm burden attributed that the vaccine acts on the immature stages rather than adult worms. This augmented by who said that the vaccination did not perfectly get rid of adult nematodes from vaccinated animals, but it caused decreasing pasture contaminations by infective larvae and subsequently decreasing the level of reinfection [52]. Thus, neutralizing the activity of GST may be a strategy to induce protection against some parasitic infections. Interestingly, there are some studies on GST of other helminthes of fantastic results. For example, used Na-GST-1 from $N$. americanus as a vaccine which currently in phase 1 clinical trial in healthy adult volunteers in the United States and Brazil. In contrast, obtained 35.71\% reduction in adult worms in mice immunized with rTsGST of Trichenella spiralis $[45,53]$. This low protection rate referred to the TsGST is a cytoplasmic protein, not an ES protein, and of low antigenicity which reflected in sufficient antibodies production by vaccination. The current results showed that immunized lambs by CAA and GST elicited high levels of circulating anti-GST Haemonchus IgG. As reported previously, antibodies might have a function in protecting immunity against $H$. contortus [54-56]. The purified antigen induced the highest effect in minimizing number of worm burden and egg count among the tested antigens. It is worthy to mention that an absence of detectable specific anti-Haemonchus $\mathrm{Ab}$ after challenge in non-immunized lambs. This matched with previous observations of [42,31]. Since no significant difference between unimmunized infected and adjuvant groups in egg count and worm burden. This denotes that the protection is due to the vaccination by GST or CAA, which was dependent on the used antigens [31].

\section{Conclusion}

In conclusion, depending on the efficacy criteria of $H$. contortus vaccine that pronounced by which must have reduction in the cumulative fecal egg count and adult abomasal worms post challenge in addition to serum anti-GST antibody levels [31]. These 
criteria were found in the lambs vaccinated by purified GST. Therefore, the present results confirmed the significant effect of GST vaccine on protection of lambs against haemonchosis. Finally, a commercial vaccine is now available to $H$. contrtus in sheep, Barbervax vaccine, was launched for commercial use in October 2014 (barbervax.com.au). This action gives us hopefulness for further development of another vaccine for Haemonchiosis from GST.

\section{Acknowledgment}

Appreciative thanks are present to the Science and Technology Development Fund (STDF) for financial aid under project number 3825.

\section{References}

1. Fawzi EM, González-Sánchez ME, Corral MJ, Cuquerella M, Alunda JM (2015) Vaccination of lambs against Haemonchus contortus infection with a somatic protein (Hc23) from adult helminthes. Int J Parasitol 44: 429-36.

2. Jabbar A, Campbell AJ, Charles JA, Gasser RB (2013) First report of anthelmintic resistance in Haemonchus contortus in alpacas in Australia. Parasite Vectors 6: 243 .

3. Benz GW, Roncalli RA, Gross SJ (1989) Use of Ivermectin in cattle, sheep, goats and swine. Ivermectin and abamectin 1989: 215-29.

4. Skuce PJ, Redmond DL, Liddell S, Stewart EM, Newlands GF, et al. (1999) Molecular cloning and characterization of gut derived cysteine proteinases associated with a host protective extract from Haemonchus contortus. Parasitology 119: 405-12.

5. Kaplan RM, Vidyashankar AN (2012) An inconvenient truth: global worming and anthelmintic resistance. Vet Parasitol 186: 70-8.

6. Roberts B, Antonopoulos A, Haslam SM, Dicker AJ, McNeilly TN, et al. (2013) Novel expression of Haemonchus contortus vaccine candidate aminopeptidase H11 using the free-living nematode Caenorhabditiselegans. Vet Res 44: 111.

7. Bassetto CC, Picharillo ME, Newlands GFJ, Smith WD, Fernandes S, et al. (2014) Attempts to vaccinate ewes and their lambs against natural infection with Haemonchus contortus in a tropical environment. Int J Parasitol 44: 1049-54.

8. Piedrafita DP, Veer MJ, Sherrard J, Kraska T, Elhay M, et al. (2012) Field vaccination of sheep with a larval-specific antigen of the gastrointestinal nematode, Haemonchus contortus, confers significant protection against an experimental challenge infection. Vaccine 30: 7199-704.

9. Degheidy NS, Sharaf EM, Al-Malki JS, Sabra SF, Hamed NM, et al. (2014) Evaluation of Coprological, Post mortum and Seroassay Techniques for the Diagnosis of Sheep Haemonchosis in Taif, KSA. Global Veterinaria 13: 672-9.

10. Mannervik B, Alin P, Guthenberg C, Jensson H, Tahir MK, et al. (1985) Identification of three classes of cytosolic glutathione transferase common to several mammalian species: correlation between structural data and enzymatic properties. Proc Natl Acad Sci USA 82: 7202-6.

11. Torres-Rivera A, Landa A (2008) Glutathione transferases from parasites: a biochemical view. Acta Trop 105: 99-112.'

12. Brophy PM, Pritchard DI (1994) Parasitic helminth glutathione S-transferases-an update on their potential as targets for immunotherapy and chemotherapy. Exp Parasitol 79: 89-96.

13. Kampkotter A, Volkmann TE, de Castro SH, Leiers B, Klotz LO, et al. (2003) Functional analysis of the glutathione S-transferase 3 from Onchocerca volvulus (Ov-GST-3): a parasite GST confers increased resistance to oxidative stress in Caenorhabditis elegans. J Mol Biol 325: 25-37.

14. García-Coiradas L, Angulo-Cubillán F, Méndez S, Larraga V, de la Fuente C, et al. (2009) Isolation and immuno- localization of a putative protective antigen (p26/23) from adult Haemonchus contortus. Parasitol Res 104: 363-9.

15. Dom'inguez-Toraño IA, Fernández-Pérez FJ, Gómez-Muñoz MT, Alunda JM, Cuquerella M (2003) Humoral and cellular response in lambs vaccinated against Haemonchus contortus with p26/23. Small Rumin Res 50: 29-37.

16. Rathaur S, Yadav M, Gupta S, Anandharaman V, Reddy MV, et al. (2008) Filarial glutathione-S-transferase: a potential vaccine candidate against lymphatic filariasis. Vaccine 26: 4094-100.

17. Veerapathran A, Dakshinamoorthy G, Gnanasekar M, Reddy MV, Kalyanasundaram R (2009) Evaluation of Wuchereria bancrofti GST as a vaccine candidate for lymphatic filariasis. PLoS Negl Trop Dis 3: e457.

18. Mbanefo EC, Kumagai T, Kodama Y, Kurosaki T, Furushima-Shimogawara R, et al. (2015) Immunogenicity and anti-fecundity effect of nanoparticle coated glutathione S-transferase (SjGST) DNA vaccine against murine Schistosoma japonicum infection. Parasitol Int 64: $24-31$.

19. Lui CY, Song YY, Ren HN, Sun GG, Liu RD, et al. (2017) Cloning and expression of a Trichinellas piralis putative glutathione S-transferase and its elicited protective immunity against challenge infections. Parasit Vectors 10: 448.

20. Mutapi F, Billingsley PF, Secor WE (2013) Infection and treatment immunizations for successful parasite vaccines. Trends Parasitol 29: 135-41.

21. Parween S, Gupta PK, Chauhan VS (2011) Induction of humoral immune response against PfMSP-1 (19) and PvMSP-1 (19) using gold nanoparticles along with alum. Vaccine 29: 2451-60.

22. Kandil OM, Abdelrahman KA, Shalaby HA, Hendawy HSM, Abu El Ezz NMT, et al. (2017) Evaluation of crude larval protein and recombinant somatic protein26/23 (rHcp26/23) immunization against Haemonchus contortus in sheep. Vet World 10: 758-63.

23. Soulsby EJL (1982) Helminths, Arthropods and Protozoa of domesticated animals (7th Edn) Bailliere Tindall, London, UK.

24. Cuquerella M, Gómez-Muñoz MT, de la Fuente C, Carrera L, Alunda JM (1993) Lamb serum recognition of infective larvae and adult Haemonchus contortus antigens. Vet Parasitol 49: 255-64.

25. Wijffels GL, Sexton JL, Salvatore L, Pettitt JM, Humphris DC, et al. (1992) Primary sequence heterogeneity and tissue expression of glutathione S-transferases of Fasciola hepatica. Exp Parasitol 74: 87-99.

26. Habig WH, Pabst MJ, Jakoby WB (1974) The first enzymatic step in mercapturic acid formation. J Bio Chem 249: 7130-9.

27. Lowry OH, Rosebrough NJ, Farr AL, Randall RJ (1951) Protein measurement with the folin and phenol reagent. J Biol Chem 193: $265-75$.

28. Fagbemi BO, Obarisiagbon IO, Mbuh JV (1995) Detection of circulating antigen in sera of Fasciola gigantica infected cattle with antibodies reactive with a Fasciola specific $88 \mathrm{kDa}$ antigen. Vet Parasitol 58: 235-46.

29. Laemmli UK (1970) Cleavage of structural protein during the assembly of the head of bacteriophage. T4. Nature London 227: 680-5. 
30. Towbin H, Staeheline T, Gordon J (1979) Electrophoretic transfer of protein From polyacrylamide gels to nitrocellulose sheets. Procedure and some applications. Proc Natl Acad Sci USA 76: 4350-4.

31. González-Sánchez ME, Cuquerella M, Alunda JM (2018) Vaccination of lambs against Haemonchus contortus with the recombinant rHc23. Effect of adjuvant and antigen dose. PLoS One 13: e0193118.

32. Charles TP, Baker NF (1988) Seasonal prevalence of GINs of beef calves grazed on irrigated pasture in the lower Sacramento valley of California. Anim J Vet Res 49: 566-71.

33. Paykari H, Dalimi A, Madani R (2002) Immunization of sheep against Fasciola gigantica with glutathione S-transferase. Vet Parasitol 105: 153-9.

34. Zhan BS, Liu S, Perally J, Xue R, Fujiwara PM, Brophy S, et al. (2005) Biochemical characterization and vaccine potential of a heme-binding glutathione transferase from the adult hookworm Ancylostoma caninum. Infect Immun 73: 6903-11.

35. Van Rossum AJ, Jefferies JR, Rijsewijk FA, LaCourse EJ, Spittle PT, et al. (2004) Binding of hematin by a new class of Glutathione transferase from the BloodFeeding Parasitic Nematode Haemonchus contortus. Infect Immun 72: 2780-90.

36. Pour LM, Farahnak A, Rad MM, Golmohamadi T, Eshraghian M (2014) Activity assay of glutathione s-transferase (GSTs) enzyme as a diagnostic biomarker for liver hydatid cyst in vitro. Iran J Public Health 43: 994-9.

37. Morrison CA, Colin T, Sexton JL, Bowen F, Wicker J, et al. (1996) Protection of cattle against Fasciola hepatica infection by vaccination with glutathione S-transferase. Vaccine 14: 1603-12.

38. Gupta S, Bhandari YP, Reddy MV, Harinath BC, Rathaur S (2005) Setariacervi immunoprophylactic potential of glutathione-S-transferase against filarial parasite Brugia malayi. Exp Parasitol 109: 252-5.

39. Zhu M, Wang X, Wang H, Wang Z, Zhao J, et al. (2015) Mechanism of protective immunity by vaccination with recombinant Echinococcus granulosus glutathione S-transferase (Chinese strain) in mice. Exp Ther Med 10: 1127-32.

40. El-Askalany MA, Mousa WM, Arafa WM, Aboelhadid SM, Mahdy EA, et al. (2012) Vaccination of Egyptian Balady goats (Capra hircus) against Haemonchus contortus with adult and larval extract. 7th conference of Faculty of veterinary Medicine, Alexanderia University, Alex J Vet Sci.

41. Fawzi EM, González-Sánchez ME, Corral MJ, Alunda JM, Cuquerella M (2014) Vaccination of lambs with the recombinant protein rHc23 elicits significant protection against Haemonchus contortus challenge. Vet Parasitol 211: 54-9.

42. Preyavichyapugdee N, Sahaphong S, Riengrojpitak S, Grams R, Viyanant V, et al. (2008) Fasciola gigantica and Schistosoma mansoni: vaccine potential of recombinant glutathione S-transferase (rFgGST26) against infections in mice. Exp Parasitol 119: 229-37.

43. Zhan B, Perally S, Brophy PM, Xue J, Goud G, et al. (2010) Molecular cloning, biochemical characterization, and partial protective immunity of the hemebinding glutathione S-transferases from the human hookworm Necatoramericanus. Infect Immun 78: 1552-63.

44. Hotez PJ, Diemert D, Bacon KM, Beaumier C, Bethony JM, et al. (2013) The human hookworm vaccine. Vaccine 31: B227-32.

45. Diemert DJ, Freire J, Valente V, Fraga CG, Talles F, et al. (2017) Safety and immunogenicity of the Na-GST-1 hookworm vaccine in Brazilian and American adults. PLoSNegl Trop Dis 11: e0005574.

46. Gennari SM, Tait A (1992) An attempt to vaccinate sheep with whole homogenate of third- stage and adult Haemonchus contortus. Rio de Janeiro 1: 31-5.

47. Sharp PJ, Smith DRJ, Bach W, Waglands BM, Cobon GS (1991) Purified glutathione S-transferases from parasites as candidate protective antigens. Int J Parasitol 21: 839-46.

48. Yang YI, Yujie M, Xueqiu C, Xiaolu G, Baolong Y, et al. (2015) Screening and analysis of Hc-ubq and Hc-gst related to desiccation survival of infective Haemonchus contortus larvae. Vet Parasitol 210: 179-85.

49. Mokhtarian K, Meamar AR, Khoshmirsafa M, Razmjou E, Masoori L, et al. (2018) Comparative assessment of recombinant and native immunogenic forms of Fasciola hepatica proteins for serodiagnosis of sheep fasciolosis. Parasitol Res 117: 225-32.

50. Schuller DJ, Liu Q, Kriksunov IA, Campbell AM, Barrett J, et al. (2005) Crystal structure of a new class of glutathione transferase from the model Human hookworm nematode Heligmosomoides polygyrus. Proteins 61: 1024-31.

51. McManus DP, Loukas A (2008) Current status of vaccines for schistosomiasis. Clin Microbiol Rev 21: 225-42.

52. Siefker C, Rickard LG (2000) Vaccination of calves with Haemonchus placei intestinal homogenate. Vet Parasitol 88: 249-60.

53. Li LG, Wang ZQ, Liu RD, Yang X, Liu LN, et al. (2015) Trichinella spiralis: Low vaccine potential of glutathione S-transferase against infections in mice. Act Trop 146: 25-32.

54. Muleke CI, Yan RF, SunYM, Zhao GW, Xu LX, et al. (2006) Vaccination of goats against Haemonchus contortus with a recombinant cysteine protease. Small Rumin Res 73: 95-102.

55. Yanming S, Ruofeng Y, Muleke CI, Guangwei Z, Lixin X, et al. (2007) Vaccination of goats with recombinant galectin antigen induces partial protection against Haemonchus contortus infection. Parasite Immunol 29: 319-26.

56. Zhao GW, Yan RF, Muleke CI, Sun YM, Xu L, et al. (2012) Vaccination of goats with DNA vaccines encoding H11 and IL-2 induces partial protection against Haemonchus contortus infection. Vet J 191: 94-100.

57. Munn EA, Smith TS, Graham M, Greenwood CA, Tavernor AS, et al. (1993) Vaccination of merino lambs against haemonchosis with membrane-associated proteins from the adult parasite. Parasitology 106: 63-6. 


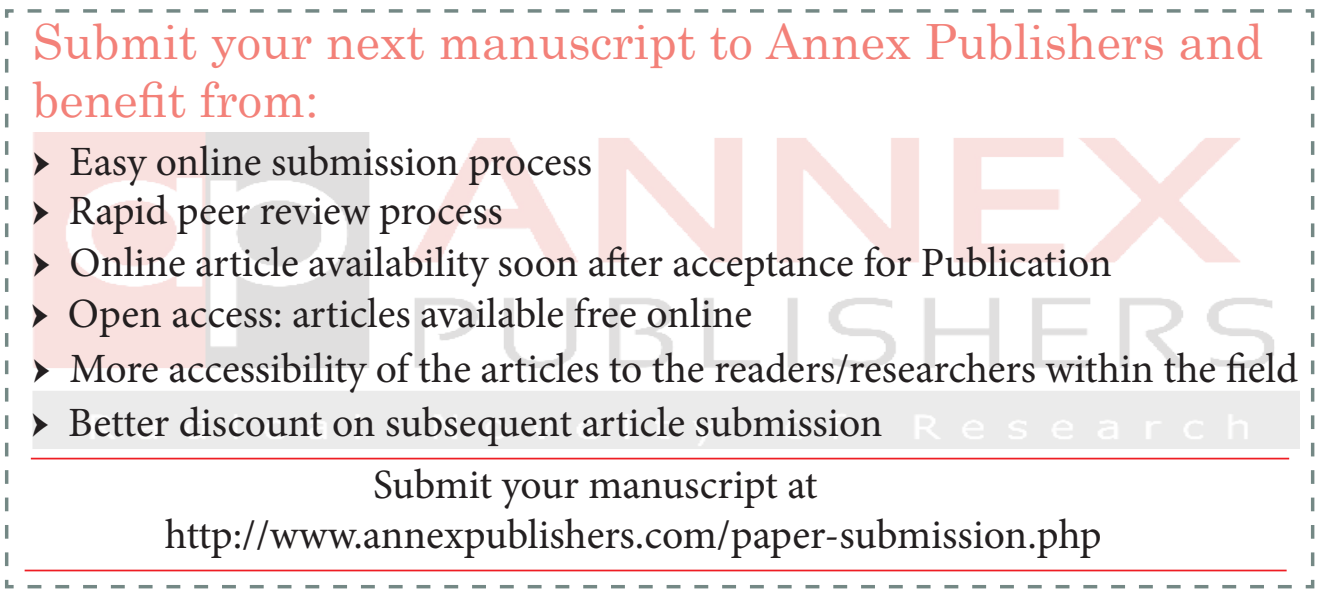

